\title{
A systematic review and meta-analysis of the efficacy of medical masks and N95 respirators for protection against respiratory infectious diseases, including COVID-19 in medical staff
}

\section{Gao-hong Wu, MM}

Children's Hospital of Soochow University, China https://orcid.org/0000-0002-2939-6008

Ping Jiang, MB

Bayingolin Mongolian autonomous prefecture people's hospital, Korla, Sinkiang 841000, China Huan Yuan, MB

Children's Hospital of Soochow University, China

\section{Yuan Shi, MD, PhD}

Children's Hospital, Chongqing Medical University, Ministry of Education Key Laboratory of Child Development and Disorders, Key Laboratory of Pediatrics in Chongqing, Chongqing, China Chongqing 400014, China

Xue-ping Zhu, MD, PhD ( $\nabla$ zhuxueping4637@hotmail.com )

Children's Hospital of Soochow University, China

\section{Systematic Review}

Keywords: Respiratory infectious diseases; COVID-19; Medical masks; N95 respirators; Meta-analysis

Posted Date: July 23rd, 2020

DOl: https://doi.org/10.21203/rs.3.rs-47687/v1

License: (a) (1) This work is licensed under a Creative Commons Attribution 4.0 International License. Read Full License 


\section{Abstract}

To evaluate the efficacy of $\mathrm{N} 95$ respirators and medical masks for protection against respiratory infectious diseases, including COVID-19. We conducted a systematic review and metaanalysis of randomized controlled trials (RCTs) and observational studies evaluating the use of N95 respirators and medical masks for protection against respiratory infectious diseases. We retrieved relevant articles published from January 1994 to January 2020 by searching the PubMed, EMBASE, Cochrane CENTRAL, and Web of Science databases. The study quality was evaluated using the Cochrane Risk of Bias tool with RevMan 5.3 software. Eleven RCTs adjusted for clustering were included in the meta-analysis. Compared with the control group, N95 respirators or medical masks conferred significant protection against respiratory infectious diseases (odds ratio $(O R)=0.50 ; 95 \% \mathrm{Cl}$ : $0.29-0.84)$. Compared to medical masks, $\mathrm{N} 95$ respirators conferred significant protection against respiratory infectious diseases ( $O R=0.75 ; 95 \%$ confidence interval $(\mathrm{Cl})$ : $0.57-0.99)$. Meta-analysis of 10 observational studies adjusting for clustering also suggested that N95 respirators and medical masks are effective for protection against respiratory infectious diseases ( $\mathrm{OR}=0.59 ; 95 \% \mathrm{Cl}: 0.42-0.82$ ). However, only one case report showed the effectiveness of medical masks for preventing COVID19. Although medical masks and N95 respirators may confer significant protection against respiratory infectious diseases, there is insufficient evidence to conclude that these types of personal protective equipment offer similar protection against COVID-19. Therefore, in the absence of sufficient resources during an epidemic, medical masks and N95 respirators should be reserved for high-risk, aerosolgenerating producing procedures.

\section{Introduction}

Respiratory infectious diseases are characterized by high infectivity and rapid epidemic contagion via multiple transmission channels that are difficult to control ${ }^{[1]}$. The outbreak of severe acute respiratory syndrome coronavirus 2 (SARS-CoV-2), which originated in Wuhan, China, has become a major global health issue. This novel coronavirus can cause severe respiratory tract infections and lead to bronchiolitis or pneumonia, a disease designated coronavirus disease 2019 (COVID-19) by the World Health Organization (WHO) on February 12, 2020. The high prevalence of SARS-Cov-2 infections led the WHO to declare this an international public health emergency on January $30,2020^{[2]}$. At present, there are no specific treatments for COVID-19, but many public health measures have been implemented to improve disease control and prevention. Medical masks and N95 respirators are a type of personal protective equipment (PPE) used by medical staff that have been shown to be highly significant for the prevention of SARS-Cov- $2^{[3]}$. During the COVID-19 pandemic, there have been reports of shortages of PPE such as N95 respirators and medical masks for medical workers ${ }^{[4]}$. There is evidence that medical masks and N95 respirators have similar protective efficacy and that N95 respirators should be reserved for aerosolgenerating procedures ${ }^{[5]}$. On the other hand, if $\mathrm{N} 95$ respirators are more effective than medical masks for 
the prevention of respiratory infectious diseases, they should be prioritized for aerosol-generating procedures. In this study, we conducted a comprehensive meta-analysis of the effectiveness of N95 respirators and medical masks for protection against respiratory infectious diseases, including COVID-19, to provide scientific basis for the formulation of policies related to the use of medical masks and other PPE.

\section{Methods}

\section{Systematic review registration}

This systematic review was registered with number CRD42020179966

(https://www.crd.york.ac.uk/PROSPERO)

\section{Search strategy}

Articles published in English from January 1994 to January 2020 which explored the relationship between wearing medical masks and protection against respiratory infectious diseases were retrieved from PubMed, EMBASE, Cochrane CENTRAL, and Web of Science databases. The following search terms were used: "Respiratory infectious diseases", "COVID-19", "respiratory tract infection", "prevention", "Medical masks" and "N95 respirators". Logical operators (OR, NOT, AND) were used to combine keywords and subject words (Table 1).

\section{Inclusion criteria}

Articles that met the following criteria were selected: This study design was peer-reviewed randomized controlled trials (RCTs) or observational studies (OSs); The population was medical staff; The exposure of interest was wearing medical masks or N95 respirators; The outcome of interest was the proportion of medical mask use in the experimental and control groups; The settings were healthcare settings worldwide.

\section{Exclusion criteria}

We excluded guidelines, editorials, public press articles, reviews, raw data unavailable, theoretical models and the articles published in languages other than English.

Table 1. Search strings for the four databases 


\begin{tabular}{|c|c|}
\hline Database & Search string \\
\hline PubMed & 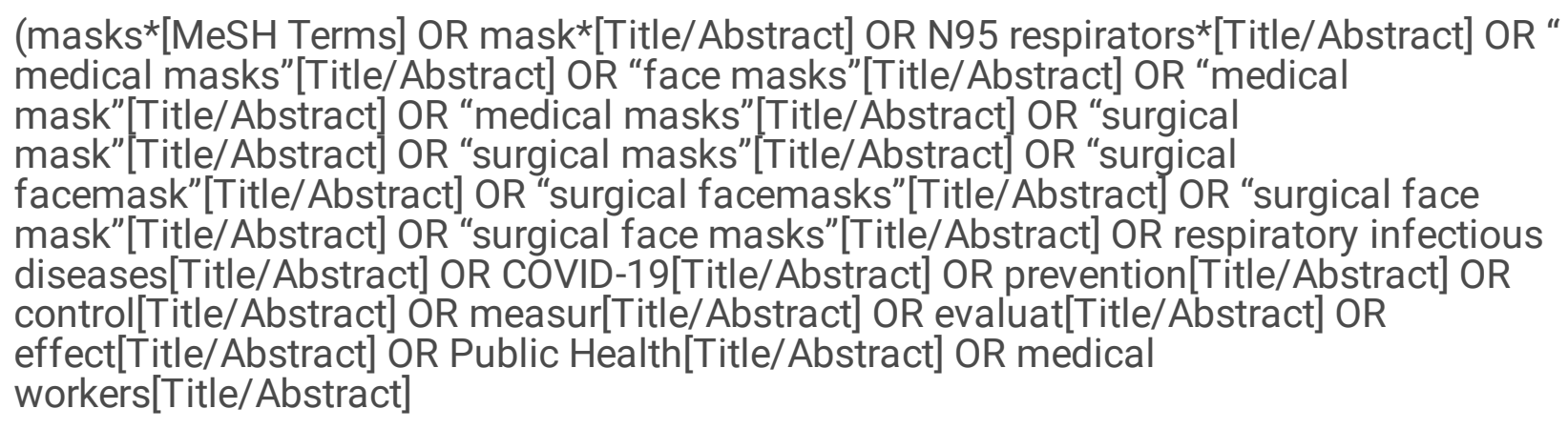 \\
\hline EMBASE & 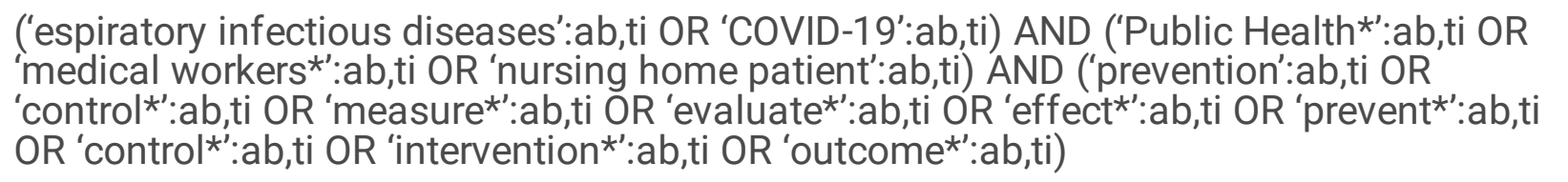 \\
\hline $\begin{array}{l}\text { Web of } \\
\text { Science }\end{array}$ & $\begin{array}{l}\text { TS=(mask" OR facemask* OR "face mask" OR "face masks" OR "medical" OR "medical } \\
\text { mask" OR "medical masks" OR "medical facemask" OR "medical facemasks" OR } \\
\text { "medical face mask" OR "medical face masks" OR "N95" OR "N95 respirators" OR } \\
\text { "surgical facemask" OR "surgical facemasks" OR "surgical face mask" OR "surgical face } \\
\text { masks" OR Infectious Diseases OR Respiratory infectious diseases OR "COVID--19" OR } \\
\text { "prevention" OR "control" OR "prevention and control" OR PPE OR "measur" OR "evaluat" } \\
\text { OR "effect" OR "Public Health" OR "medical workers") AND TS=( "healthcare worker" OR } \\
\text { "healthcare workers" OR "health care worker" OR "health care workers" OR "health-care } \\
\text { worker" OR "health-care workers" OR "healthcare professional" OR "healthcare } \\
\text { professionals" OR "health care professional" OR "health care professionals" OR "health- } \\
\text { care professional" OR "health-care professionals" OR staff OR "healthcare personnel" OR } \\
\text { "health care personnel" OR "health-care personnel") }\end{array}$ \\
\hline $\begin{array}{l}\text { Cochrane } \\
\text { CENTRAL }\end{array}$ & $\begin{array}{l}\text { Respiratory infectious diseases OR COVID-19 in Title, Abstract, Keywords, AND 'medical } \\
\text { masks' OR 'N95 respirators' OR 'mask' in Title, Abstract, Keywords, AND practice OR } \\
\text { control* OR measur* OR evaluat* OR effect OR prevent* OR prevention and control* OR } \\
\text { intervention* OR outcome* in Title, Abstract, Keywords,, Publication Year from } 1994 \text { to } \\
2020 \text { in Trials }\end{array}$ \\
\hline
\end{tabular}

\section{Data extraction}

Data extraction was conducted in two stages: first, the literature was screened by two researchers according to inclusion criteria. The screened literature was then searched and evaluated by two other researchers according to the inclusion criteria and exclusion criteria. To avoid errors, a pre-designed form was used to select the study characteristics, baseline patient characteristics, outcomes and definitions included in the literature, and any inconsistencies in recommendations were resolved through consultation. The main data extracted were as follows: the number of medical staff who insisted on wearing masks and those who did not insist on wearing masks.

\section{Literature quality assessment}

The quality of the methodology in the included studies was evaluated by using Cochrane Risk of Bias tool $^{[6]}$. The quality of RCTs was evaluated using RevMan 5.3 software. The risk of bias was evaluated from six perspectives: choice bias, performance bias, measurement bias, attrition bias, reporting bias, 
other biases (Table 2). According to the criteria for low, unclear and high risk, the quality of the methodology of the included studies was divided into three levels as follows: Mild bias: four or more of the above six items are low risk; moderate bias: two or three of the above six items are low risk; severe bias: none or only one of the above six items is low risk.

Table 2 Cochrane risk of bias assessment form

\begin{tabular}{|c|c|c|}
\hline Evaluation & \multicolumn{2}{|c|}{ Evaluation content } \\
\hline \multirow[t]{2}{*}{ Choice bias } & $\begin{array}{l}\text { Random } \\
\text { sequence } \\
\text { generation }\end{array}$ & $\begin{array}{l}\text { The method of generating random assignment sequence is } \\
\text { described in detail, which is convenient for evaluation of the } \\
\text { comparability between groups. }\end{array}$ \\
\hline & $\begin{array}{l}\text { Assignment } \\
\text { hidden }\end{array}$ & $\begin{array}{l}\text { The method of hiding random distribution sequence is described in } \\
\text { detail, which is convenient for judging whether the distribution of } \\
\text { intervention measures can be predicted. }\end{array}$ \\
\hline $\begin{array}{l}\text { Performance } \\
\text { bias }\end{array}$ & $\begin{array}{l}\text { Blind } \\
\text { method for } \\
\text { researchers } \\
\text { and } \\
\text { subjects }\end{array}$ & $\begin{array}{l}\text { The method of blinding used to prevent researchers and subjects } \\
\text { from knowing the intervention measures is described in detail. This } \\
\text { provides information that can be used to judge whether the blinding } \\
\text { method is effective. }\end{array}$ \\
\hline $\begin{array}{l}\text { Measurement } \\
\text { bias }\end{array}$ & $\begin{array}{l}\text { Blind } \\
\text { evaluation } \\
\text { of research } \\
\text { results }\end{array}$ & $\begin{array}{l}\text { The method of blinding used to prevent the evaluators of the } \\
\text { research results from knowing the intervention measures is described } \\
\text { in detail. This provides information that can be used to judge } \\
\text { whether the blinding method is effective. }\end{array}$ \\
\hline Attrition bias & $\begin{array}{l}\text { Integrity of } \\
\text { result data }\end{array}$ & $\begin{array}{l}\text { The data for each major outcome indicator, including those of } \\
\text { subjects who were lost or withdrew from the study, are reported } \\
\text { completely. Including subjects who were lost or withdrew, the total } \\
\text { number of people in each group (compared with the total number of } \\
\text { randomly enrolled people), and the reasons for the loss of } \\
\text { interview/withdrawal are clearly reported, so as to facilitate } \\
\text { assessment of the relevant treatment by the system evaluator. }\end{array}$ \\
\hline $\begin{array}{l}\text { Reporting } \\
\text { bias }\end{array}$ & $\begin{array}{l}\text { Selective } \\
\text { reporting of } \\
\text { research } \\
\text { results }\end{array}$ & $\begin{array}{l}\text { The information described can be used by system evaluators to } \\
\text { judge the possibility of selective reporting of research results and } \\
\text { relevant information. }\end{array}$ \\
\hline Other biases & $\begin{array}{l}\text { Other } \\
\text { sources of } \\
\text { bias }\end{array}$ & $\begin{array}{l}\text { In addition to the above biases, the information provided can be used } \\
\text { to assess the existence of other bias factors. If a question or factor is } \\
\text { mentioned in the plan, corresponding answers are required. }\end{array}$ \\
\hline
\end{tabular}

\section{Statistical methods}

RevMan 5.3 software provided by the Cochrane Collaboration was used to conduct this meta-analysis of the proportions of medical mask use between the experimental and control groups. $Q$ and $P$ tests were used to evaluate the heterogeneity of the included studies ( $Q$ tests is the traditional method in the 
heterogeneity test of meta-analysis; $P$ tests can measure the degree of difference among multiple research effects, and can describe the percentage of variation caused by inter research in the total variation). When $R \leq 50 \%$ and $P>0.1$, a fixed effect model was used to merge the data; when $R>50 \%$ or $P<0.1$, a random effect model was used to merge the data. The odds ratio (OR) and $95 \%$ confidence interval $(\mathrm{Cl})$ were used to express the enumeration data. $P<0.05$ was considered to indicate statistical significance.

\section{Results}

\section{Literature search results}

After searching 350 papers from four databases , 21 articles were included in the final screening (Figure 1). We searched the full text of 230 articles and excluded 209 that did not meet our inclusion criteria. Finally, we selected 11 RCTs (Table 3A, 3B) and 10 OSs (Table 4). Five of the RCTs analyzed the effectiveness of $\mathrm{N} 95$ respirators versus medical masks for protection against respiratory infectious diseases. There was no real evidence to suggest publication bias (Figure 2A, 2B, 2C).

Table 3A. Summary of RCTs assessing the effectiveness of masks for protection against respiratory infectious diseases $(\mathrm{n}=7$ ). 


\begin{tabular}{|c|c|c|c|c|c|c|c|c|c|c|}
\hline \multirow[t]{2}{*}{ Author } & \multirow[t]{2}{*}{ Journal } & \multirow{2}{*}{$\begin{array}{l}\text { Year of } \\
\text { publication }\end{array}$} & \multirow{2}{*}{$\begin{array}{l}\text { Study } \\
\text { design }\end{array}$} & \multirow{2}{*}{$\begin{array}{l}\text { Mask } \\
\text { type }\end{array}$} & \multicolumn{2}{|c|}{$\begin{array}{l}\text { Experimental group } \\
\text { (n) }\end{array}$} & \multicolumn{2}{|c|}{ Control group (n) } & \multirow[t]{2}{*}{ OR } & \multirow[t]{2}{*}{$95 \% \mathrm{CI}$} \\
\hline & & & & & Infected & $\begin{array}{l}\text { Non- } \\
\text { infected }\end{array}$ & Infected & $\begin{array}{l}\text { Non- } \\
\text { infected }\end{array}$ & & \\
\hline Steo $^{[7]}$. China & Lancet & 2003 & RCTs & N95 & 0 & 13 & 92 & 149 & 0.06 & $\begin{array}{l}0.00- \\
1.02\end{array}$ \\
\hline Al-Asmary ${ }^{[8]}$. & IntJ Infect Dis & 2007 & RCTs & N95 & 18 & 92 & 4 & 14 & 0.68 & $0.20-$ \\
\hline Arabia & & & & & & & & & & 2.32 \\
\hline $\mathrm{Ng}^{[9]}$. China & $\begin{array}{c}\text { Infect Control Hosp } \\
\text { Epidemiol }\end{array}$ & 2008 & RCTs & Medical & 10 & 83 & 20 & 20 & 0.12 & $\begin{array}{l}0.05- \\
0.30\end{array}$ \\
\hline Yang ${ }^{[10]}$.China & Braz J Infect Dis & 2010 & RCTs & Medical & 73 & 88 & 44 & 76 & 1.43 & $\begin{array}{l}0.88- \\
2.32\end{array}$ \\
\hline MacIntyre $^{[11]}$. & INFLUENZA OTHER & 2011 & RCTs & N95 & 3 & 946 & 6 & 475 & 0.25 & $0.06-$ \\
\hline Australia & $R E S P$ & & & & & & & & & 1.01 \\
\hline MacIntyre ${ }^{[11]}$ & INFLUENZA OTHER & 2011 & RCTs & Medical & 13 & 479 & 15 & 466 & 0.84 & $0.40-$ \\
\hline Australia & $R E S P$ & & & & & & & & & 1.79 \\
\hline MacIntyre $^{[12]}$ & Prev Med & 2014 & RCTs & N95 & 31 & 918 & 39 & 442 & 0.38 & $0.24-$ \\
\hline Australia & & & & & & & & & & 0.62 \\
\hline MacIntyre ${ }^{[12]}$ & Prev Med & 2014 & RCTs & Medical & 32 & 460 & 39 & 442 & 0.79 & $0.49-$ \\
\hline Australia & & & & & & & & & & 1.28 \\
\hline MacIntyre ${ }^{[13]}$ & BMJ Open & 2015 & RCTs & Medical & 15 & 561 & 25 & 440 & 0.47 & $0.25-$ \\
\hline Australia & & & & & & & & & & 0.90 \\
\hline
\end{tabular}

Table 3B. Summary of RCTs assessing the effectiveness of medical masks versus N95 respirators for protection against respiratory infectious diseases $(n=6)$ 


\begin{tabular}{|c|c|c|c|c|c|c|c|c|c|}
\hline \multirow[t]{4}{*}{ Author } & \multirow[t]{4}{*}{ Journal } & \multirow{4}{*}{$\begin{array}{c}\text { Year of } \\
\text { publication }\end{array}$} & \multirow{4}{*}{$\begin{array}{l}\text { Study } \\
\text { design }\end{array}$} & \multicolumn{2}{|c|}{ N95 group (n) } & \multicolumn{2}{|c|}{ Medical group (n) } & \multirow[t]{4}{*}{ OR } & \multirow[t]{4}{*}{$95 \% \mathrm{CI}$} \\
\hline & & & & Infected & Non- & Infected & & & \\
\hline & & & & & infected & & Non- & & \\
\hline & & & & & & & infected & & \\
\hline \multirow[t]{2}{*}{ Loeb $^{[14]}$. Canada } & $J A M A$ & 2009 & RCTs & 126 & 663 & 113 & 675 & 1.14 & $0.86-$ \\
\hline & & & & & & & & & 1.50 \\
\hline MachIntyre ${ }^{[15]}$. & Int J Infect Dis & 2009 & RCTs & 25 & 533 & 34 & 248 & 0.34 & $0.20-$ \\
\hline Australia & & & & & & & & & 0.59 \\
\hline MachIntyre $^{[11]}$. & Influenza and Other & 2011 & RCTs & 19 & 2828 & 21 & 1455 & 0.47 & $0.25-$ \\
\hline Australia & Respiratory Viruses & & & & & & & & 0.87 \\
\hline MachIntyre $^{[16]}$. & Am J Respir Crit Care Med & 2013 & RCTs & 58 & 2266 & 73 & 1991 & 0.70 & $0.49-$ \\
\hline Australia & & & & & & & & & 0.99 \\
\hline MacIntyre $^{[12]}$. & Prev Med & 2014 & RCTs & 43 & 906 & 41 & 901 & 1.04 & $0.67-$ \\
\hline Australia & & & & & & & & & 1.62 \\
\hline Radonovich $^{[17]}$. & JAMA & 2019 & RCTs & 650 & 6886 & 776 & 7228 & 0.88 & $0.79-$ \\
\hline USA & & & & & & & & & 0.98 \\
\hline
\end{tabular}

Table 4. Summary of OSs assessing the effectiveness of masks for protection against respiratory infectious diseases $(\mathrm{n}=10)$. 


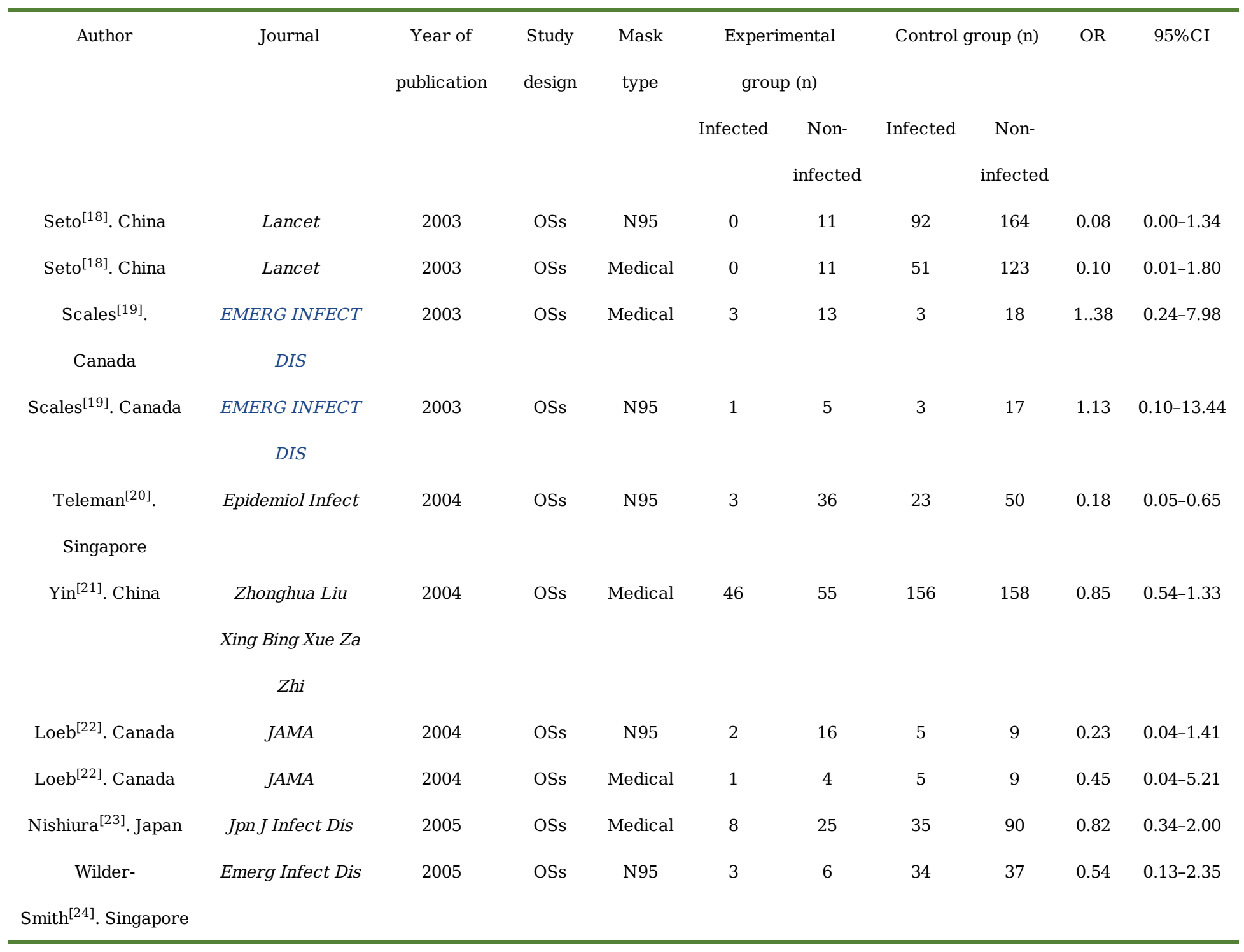

\section{Randomized controlled trials}

Assessment of the risk bias of $11 \mathrm{RCTs}{ }^{[7-17]}$ using RevMan 5.3 software showed moderate overall bias (Figure 3A, 3B).

\section{Medical mask use versus no medical mask use for protection against respiratory infectious diseases}

Nine RCTs compared respiratory infectious diseases risk in medical staff wearing masks to that of convenience-selected controls wearing no masks. Wearing N95 respirators or medical masks conferred significantly greater protection against respiratory infectious diseases $(\mathrm{OR}=0.50 ; 95 \% \mathrm{Cl}$ : $0.29-0.84 ; P<$ 0.05) (Figure 4A). Because of heterogeneity, the data were divided into medical masks and N95 respirators for subgroup analysis. Subgroup analysis showed that heterogeneity of the data for medical mask use was $R=83 \%(P<0.00001)$ and the heterogeneity for $\mathrm{N} 95$ respirator use was $R=0 \%(P=0.39)$, showing that the heterogeneity of the data for $\mathrm{N} 95$ respirator use was very small, while the heterogeneity 
of the data for medical mask use was very large. Therefore, the possibility that the heterogeneity of the data in the included studies was related to the type of mask used could not be excluded (Figure 4B).

\section{Medical mask use versus $N 95$ respirator use for protection against respiratory infectious diseases}

Six RCTs compared the use of medical masks and N95 respirators for protection against respiratory infectious diseases ${ }^{[11,12,14-17]}$. Compared with medical masks, N95 respirators were significantly more effective in protecting against respiratory infectious diseases $(\mathrm{OR}=0.75 ; 95 \% \mathrm{Cl}$ : $0.57-0.99 ; P<0.05)$ (Figure 5).

\section{Observational studies}

Assessment of the risk bias of nine OSs ${ }^{[16-24]}$ using RevMan 5.3 software showed moderate overall bias (Figure 6A, 6B).

\section{Medical mask use versus no medical mask use for protection against respiratory infectious diseases}

Ten OSs compared respiratory infectious diseases risk in medical staff wearing masks with that of convenience-selected controls wearing no masks. Wearing medical masks or N95 respirators conferred significantly greater protection against respiratory infectious diseases $(\mathrm{OR}=0.59 ; 95 \% \mathrm{Cl}: 0.42-0.82 ; P<$ 0.05) (Figure 7A). Because of heterogeneity, the data were divided into medical masks and N95 respirators for subgroup analysis. Subgroup analysis showed that heterogeneity of the data for medical mask use was $P^{2}=0 \%(P=0.61)$, and the heterogeneity for $\mathrm{N} 95$ respirator use was ${ }^{2}=0 \%(P=0.49)$, showing that the heterogeneity of the data for $\mathrm{N} 95$ respirator use was very small, while the heterogeneity of the data for both medical mask and N95 respirator use was very small. Therefore, the heterogeneity of the data in the included studies has little relationship with difference in the use of medical masks or N95 respirators and may be caused by other factors (Figure 7B).

\section{Discussion}

Both the RCTs and OSs included in this meta-analysis showed that the use of N95 respirators or medical masks has a significantly greater protective effect against respiratory infectious diseases among medical workers compared with those who did not use these types of PPE. Furthermore, although our metaanalysis showed that $\mathrm{N} 95$ respirators provide better protection against respiratory infectious diseases than medical masks, there is no convincing evidence that medical masks are inferior to N95 respirators, especially in routine care and during non-aerosol-generating procedures. Medical masks have also been reported to be similarly effective to N95 respirators in preventing influenza infection ${ }^{[17]}$. For a few respiratory infectious diseases, our meta-analysis suggested that N95 respirators were more protective than medical masks; however, the confidence intervals were wide and there was considerable heterogeneity $(P=0.0008, R=76 \%)$. This heterogeneity may have been due to differences in the inclusion and exclusion criteria among the studies (Figure 5). It should be noted that we have not yet searched for 
RCTs comparing the use of medical masks with N95 respirators for protection against SARS-CoV-2 infection and this issue is worthy of consideration.

National and international guidelines unanimously recommend the use of N95 respirators for protection against aerosols; however, this is inconsistent with the current recommendations for non-aerosol prophylaxis and routine care for COVID-19 patients ${ }^{[25-28]}$. Although medical masks are cheaper, the European Centers for Disease Control and Prevention and the Centers for Disease Control and Prevention still recommend $\mathrm{N} 95$ respirators for non-aerosol-generating procedures ${ }^{[29]}$. Indeed, Kobayashi et al. argued that long-term use and reuse of N95 respirators during the COVID-19 pandemic could effectively protect volunteer workers ${ }^{[30]}$. In contrast, the WHO and the Public Health Agency of Canada recommend the use of medical masks during the care of patients with COVID-19 ${ }^{[29]}$. $\mathrm{Ng}$ et al. published a case report on the use of respiratory devices for protection against COVID-19 ${ }^{[31]}$. Thirty-five of the 41 medical workers wore medical masks. Despite exposure to a patient with severe pneumonia who tested positive for SARSCoV-2 nucleic acids, all of these medical staff tested negative for SARS-CoV-2 nucleic acids 14 days later ${ }^{[31]}$. Thus, among the studies included in our analysis, this case report provides the only direct evidence of the protective effects of medical masks against SARS-CoV-2 infection. Therefore, the effectiveness of mask use for protection against COVID-19 remains to be fully clarified.

There are some limitations to this meta-analysis. First, the number of included studies is small, and therefore, may result in distribution bias. Analysis of a greater number of studies is required to reduce the risk of distribution bias. Second, there may be measurement bias, publication bias and selection bias in the included articles. Third, the limitations of the underlying studies, beyond just the biases, For instance, the Radonovich et al. (2019) RCT did not really control for consistency of use between its medical mask and N95 groups ${ }^{[17]}$, so its conclusions about non-inferiority may be swayed by differential consistency in use among healthcare personnel assigned to the various groups within the study. Further studies with high-quality methodology and strictly defined inclusion and exclusion criteria are required. Fourth, heterogeneity among the data in the included studies was identified, which may be related to the research population, region, and virus species. Although the subgroup analysis of the use of N95 respirators and medical masks was conducted for some indicators in this study, it was not conducted for different populations, virus species and other types of masks. Therefore, more detailed subgroup analysis is required to provide a more convincing basis for our conclusions. Fifth, the source of infection was not identified in all trials and some medical staff may have been infected before the trial. Finally, at present, the protective effects of $\mathrm{N} 95$ respirators and medical masks against SARS-CoV-2 infection have not been studied specifically; therefore, therefore, it is not possible to extend our conclusion to the situation for SARS-CoV-2.

\section{Conclusions}

Here, we conducted a literature review and meta-analysis of RCTs and OSs of the protective effects of N95 respirators and medical masks against respiratory infectious diseases, including COVID-19. Our 
analysis provides evidence to support the universal use of N95 respirators and medical masks in the medical and healthcare environment. However, the effectiveness of masks for protection against COVID19 remains to be established.

\section{Declarations}

\section{Acknowledgements}

None.

\section{Author Contributions}

GW participated in the study design and writing of the manuscript; PJ and HY participated in the English grammar correction and writing of the manuscript; $Y S$ and $X Z$ participated in analysis and writing of the manuscript. All authors read and approved the final manuscript.

\section{Competing financial interests}

The authors declare no competing financial interests.

\section{Funding source}

This study was financially supported by the The National Natural Science Foundation of China (NSFC, No. 81971423); The Jiangsu Provincial Maternal and Child Health Key Talents Project (No. FRC201731); Clinical Study of Prevention and Control System of New Coronavirus Infection in Neonates (SYS2020030).

\section{References}

1. Shi, T. et al. Global, regional, and national disease burden estimates of acute lower respiratory infections due to respiratory syncytial virus in young children in 2015: a systematic review and modelling study. Lancet 390, 946-958, doi:10.1016/S0140-6736(17)30938-8 (2017).

2. Huang, C. et al. Clinical features of patients infected with 2019 novel coronavirus in Wuhan, China. Lancet 395, 497-506, doi:10.1016/S0140-6736(20)30183-5 (2020).

3. The Lancet. COVID-19: protecting health-care workers. Lancet 395, 922, doi:10.1016/S01406736(20)30644-9 (2020).

4. Ali, Y. et al. Personal protective equipment in the response to the SARS-CoV-2 outbreak-A letter to the editor on "World Health Organization declares global emergency: A review of the 2019 novel coronavirus (COVID-19)" (Int J Surg 2020; 76:71-6). Int J Surg 78, 66-67, doi:10.1016/j.ijsu.2020.04.051 (2020).

5. Maclntyre, C. R. et al. The efficacy of medical masks and respirators against respiratory infection in healthcare workers. Influenza Other Respir Viruses 11, 511-517, doi:10.1111/irv.12474 (2017). 
6. Michaelis, R. et al. Cochrane systematic review and meta-analysis of the impact of psychological treatments for people with epilepsy on health-related quality of life. Epilepsia 59, 315-332, doi:10.1111/epi.13989 (2018).

7. Seto, W. H. et al. Effectiveness of precautions against droplets and contact in prevention of nosocomial transmission of severe acute respiratory syndrome (SARS). Lancet 361, 1519-1520, doi:10.1016/s0140-6736(03)13168-6 (2003).

8. Al-Asmary, S. et al. Acute respiratory tract infections among Hajj medical mission personnel, Saudi Arabia. Int J Infect Dis 11, 268-272, doi:10.1016/j.ijid.2006.04.008 (2007).

9. $\mathrm{Ng}, \mathrm{T}$. C. et al. Preventing healthcare workers from acquiring influenza. Infect Control Hosp Epidemiol 30, 292-295, doi:10.1086/595690 (2009).

10. Yang, P. et al. Mask-wearing and respiratory infection in healthcare workers in Beijing, China. Braz J Infect Dis 15, 102-108, doi:10.1016/S1413-8670(11)70153-2 (2011).

11. Maclntyre, C. R. et al. A cluster randomized clinical trial comparing fit-tested and non-fit-tested N95 respirators to medical masks to prevent respiratory virus infection in health care workers. Influenza and Other Respiratory Viruses 5, 170-179, doi:10.1111/j.1750-2659.2011.00198.x (2011).

12. Maclntyre, C. R. et al. Efficacy of face masks and respirators in preventing upper respiratory tract bacterial colonization and co-infection in hospital healthcare workers [published correction appears in Prev Med. 2014 Dec;69:165]. Prev Med 62, 1-7, doi:10.1016/j.ypmed.2014.01.015 (2014).

13. Maclntyre, C. R. et al. A cluster randomised trial of cloth masks compared with medical masks in healthcare workers. BMJ Open 5, e006577, doi:10.1136/bmjopen-2014-006577 (2015).

14. Loeb, M. et al. Surgical mask vs N95 respirator for preventing influenza among health care workers: a randomized trial. JAMA 302, 1865-1871, doi:10.1001/jama.2009.1466 (2009).

15. Maclntyre, C. R. et al. Face mask use and control of respiratory virus transmission in households. Emerg Infect Dis 15, 233-241, doi:10.3201/eid1502.081167 (2009).

16. Maclntyre, C. R. et al. A randomized clinical trial of three options for N95 respirators and medical masks in health workers. Am J Respir Crit Care Med 187, 960-966, doi:10.1164/rccm.201207$11640 \mathrm{C}$ (2013).

17. Radonovich, LJ. Jr. et al. N95 Respirators vs Medical Masks for Preventing Influenza Among Health Care Personnel: A Randomized Clinical Trial. JAMA 322, 824-833, doi:10.1001/jama.2019.11645 (2019).

18. Seto, W. H. et al. Effectiveness of precautions against droplets and contact in prevention of nosocomial transmission of severe acute respiratory syndrome (SARS). Lancet 361, 1519-1520, doi:10.1016/s0140-6736(03)13168-6 (2003).

19. Scales, D. C. et al. Illness in Intensive Care Staff after Brief Exposure to Severe Acute Respiratory Syndrome. Emerging Infectious Diseases 9, 1205-1210, doi:10.3201/eid0910.030525 (2003).

20. Teleman, M. D. et al Factors associated with transmission of severe acute respiratory syndrome among health-care workers in Singapore. Epidemiol Infect 132, 797-803, doi:10.1017/s0950268804002766 (2004). 
21. Yin, W. W. et al. [Effectiveness of Personal Protective Measures in Prevention of Nosocomial Transmission of Severe Acute Respiratory Syndrome] Zhonghua Liu Xing Bing Xue Za Zhi 25, 18-22 (2004).

22. Loeb, M. et al. Surgical mask vs $\mathrm{N} 95$ respirator for preventing influenza among health care workers: a randomized trial. JAMA 302, 1865-1871, doi:10.1001/jama.2009.1466 (2009)

23. Nishiyama, A. et al. Risk factors for SARS infection within hospitals in Hanoi, Vietnam. Jpn J Infect Dis 61, 388-390 (2008).

24. Wilder-Smith, A. et al. Asymptomatic SARS coronavirus infection among healthcare workers, Singapore. Emerg Infect Dis 11, 1142-1145, doi:10.3201/eid1107.041165 (2005).

25. Wang, M. E. et al. Clinical Guideline Highlights for the Hospitalist: Diagnosis and Management of Measles. J Hosp Med 15, 47-48, doi:10.12788/jhm.3346 (2020).

26. Wang, D. et al. Clinical Characteristics of 138 Hospitalized Patients With 2019 Novel CoronavirusInfected Pneumonia in Wuhan, China [published online ahead of print, 2020 Feb 7]. JAMA 323, 10611069. doi:10.1001/jama.2020.1585 (2020).

27. World Health Organization (WHO). Rational use of personal protective equipment for coronavirus disease 2019 (COVID-19). https://apps.who.int/iris/bitstream/handle/10665/331215/WHO-2019nCov-IPCPPE_use-2020.1-eng.pdf. Accessed March 17, 2020. (2020).

28. Public Health Agency of Canada (PHAC). Coronavirus disease (COVID-19): For health professionals. https://www.canada.ca/en/public-health/services/diseases/2019-novel -coronavirusinfection/health-professionals.html\#i (2020).

29. Bartoszko, J. J. et al. Medical masks vs N95 respirators for preventing COVID-19 in healthcare workers: A systematic review and meta-analysis of randomized trials [published online ahead of print, 2020 Apr 4]. Influenza Other Respir Viruses 14, 365-373, doi:10.1111/irv.12745 (2020).

30. Kobayashi, L. M. et al. Extended use or reuse of N95 respirators during COVID-19 pandemic: an overview of national regulatory authorities' recommendations [published online ahead of print, 2020 Apr 22]. Infect Control Hosp Epidemiol 2020, 1-3. doi:10.1017/ice.2020.173 (2020).

31. Ng, K. et al. COVID-19 and the Risk to Health Care Workers: A Case Report [published online ahead of print, 2020 Mar 16]. Ann Intern Med 172, 766-767. doi:10.7326/L20-0175 (2020).

\section{Figures}



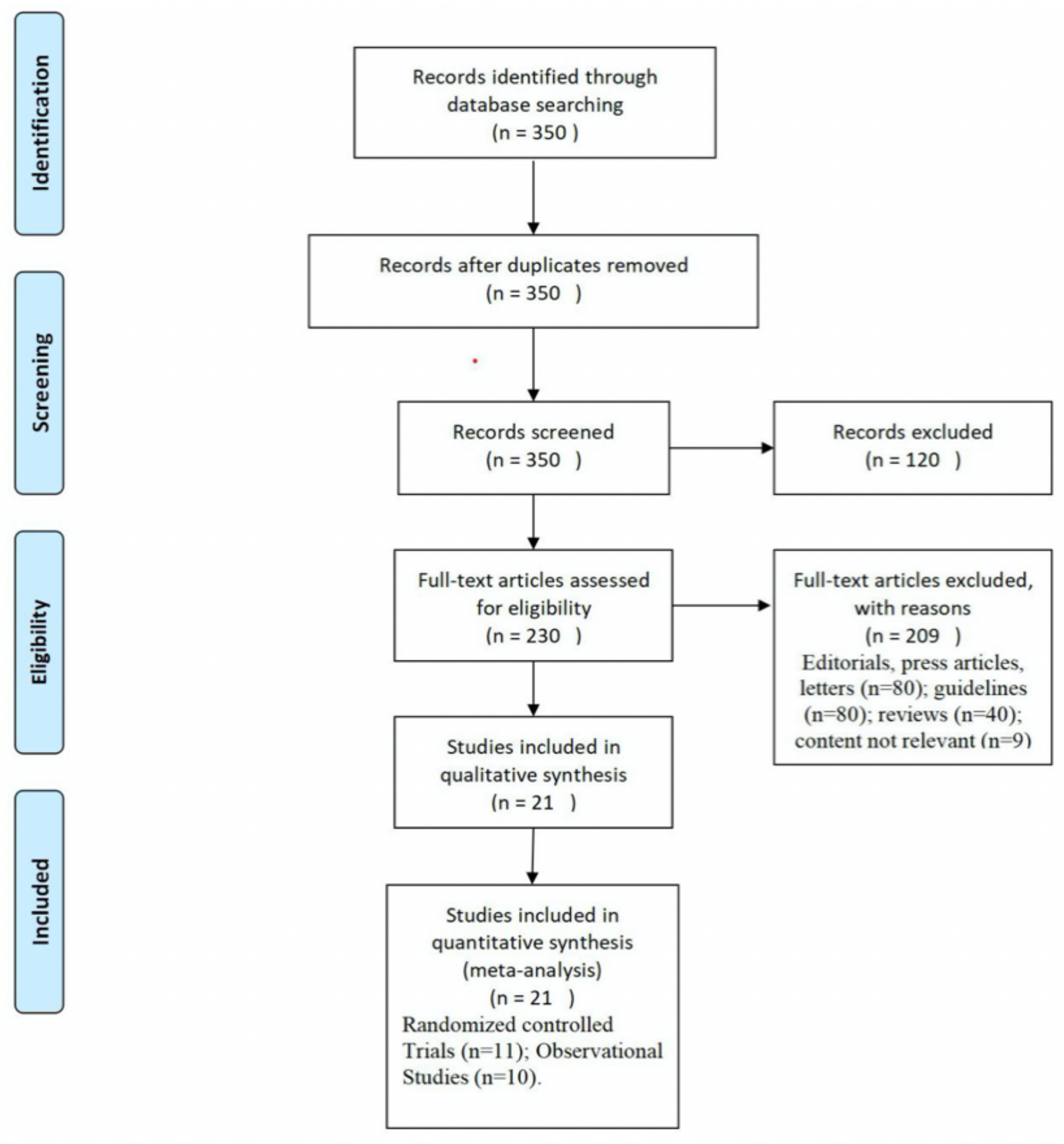

\section{Figure 1}

Summary of the literature search and inclusion process. 

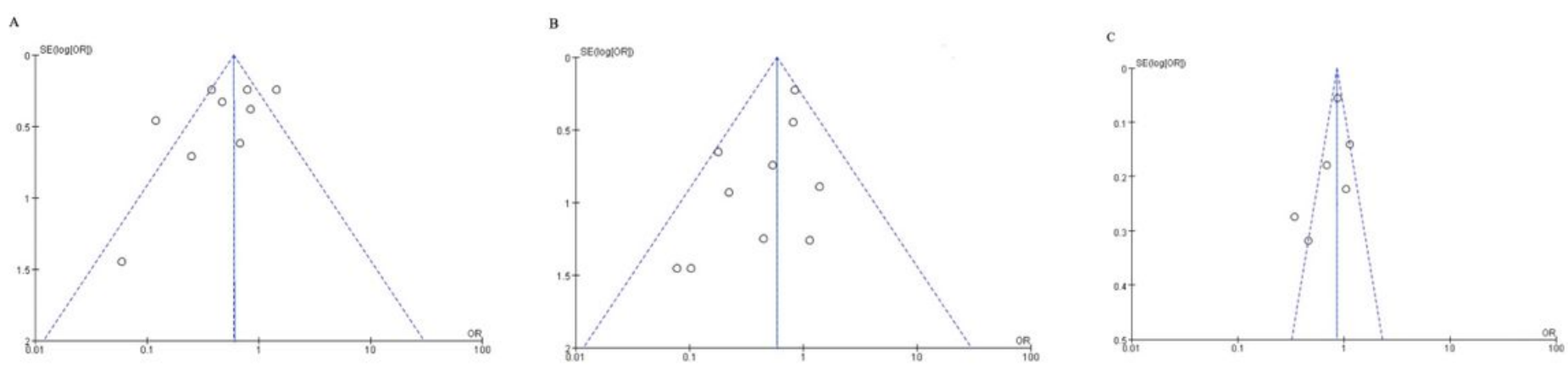

\section{Figure 2}

A. RCTs effect of mask compared to no mask. Funnel plot assessing publication bias in RCTs investigating the effectiveness of medical masks for protection against respiratory infectious diseases; Harbord's estimated bias coefficient: $-0.58 ; \mathrm{P}=0.599$. B. OSs effect of mask compared to no mask Funnel plot assessing publication bias in OSs comparing the effectiveness of masks for protection against respiratory infectious diseases; Harbord's estimated bias coefficient: $0.40 ; P=0.635$. C.RCTs effect of N95 respirators compared to medical masks Funnel plot assessing publication bias in RCTs investigating the effectiveness of medical masks and N95 respirators for protection against respiratory infectious diseases; Harbord's estimated bias coefficient: $-0.44 ; P=0.491$. Funnel plots were generated to evaluate publication bias in RCT and OSs. The unadjusted effect estimates in some studies correspond to their standard errors. The real line and dotted line represent the aggregate effect estimates of different standard errors and their $95 \% \mathrm{Cl}$, respectively. To determine publication bias, the Harbord test of smallstudy effects was used to assess funnel plot asymmetry. RCTs, randomized controlled trials; OSs, observational Studies; $\mathrm{Cl}$, confidence interval, $\mathrm{OR}$, the odds ratio. 
A

\begin{tabular}{|c|c|c|c|c|c|c|c|}
\hline & 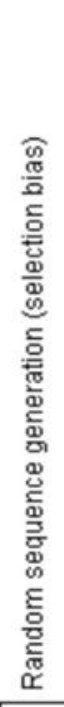 & 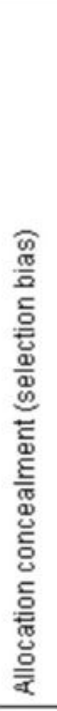 & 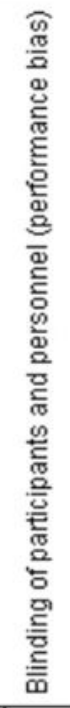 & 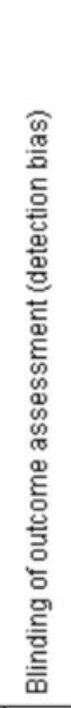 & 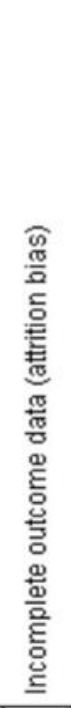 & 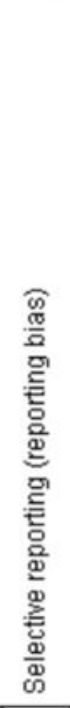 & 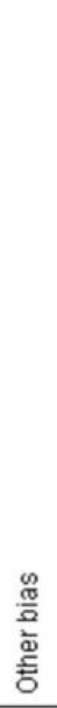 \\
\hline Al-Asmary 2007 & + & 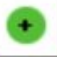 & $?$ & $?$ & $?$ & $?$ & $?$ \\
\hline Loeb 2009 & $?$ & $?$ & 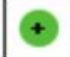 & $?$ & 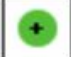 & 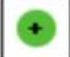 & $?$ \\
\hline MachIntyre 2009 & + & $\oplus$ & $?$ & $?$ & + & $?$ & $?$ \\
\hline MachIntyre 2011 & $?$ & $?$ & $\odot$ & $?$ & $?$ & + & 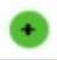 \\
\hline Machintyre 2013 & + & $?$ & 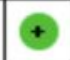 & $?$ & $?$ & $?$ & $?$ \\
\hline MachIntyre 2014 & + & $?$ & + & + & $?$ & $?$ & $?$ \\
\hline Macintyre 2015 & $?$ & $?$ & $?$ & $?$ & $?$ & 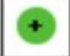 & + \\
\hline $\mathrm{Ng} 2008$ & $?$ & $?$ & $\bullet$ & $?$ & 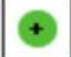 & 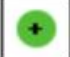 & $?$ \\
\hline Radonovich 2019 & + & $?$ & $?$ & + & $?$ & + & $?$ \\
\hline Steo 2003 & $?$ & $\oplus$ & $?$ & + & $?$ & $?$ & + \\
\hline Yang 2010 & $?$ & $?$ & $?$ & 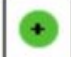 & $\oplus$ & $\theta$ & $?$ \\
\hline
\end{tabular}

B

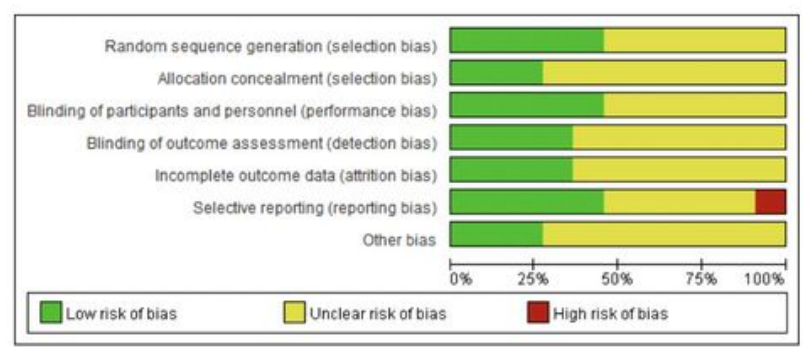

Figure 3

A. RCTs received a high (red), low (green) or uncertain (yellow) risk of bias score for each of the domains.

B. Percentage of RCTs with high, low or uncertain risk of bias in each domain. 


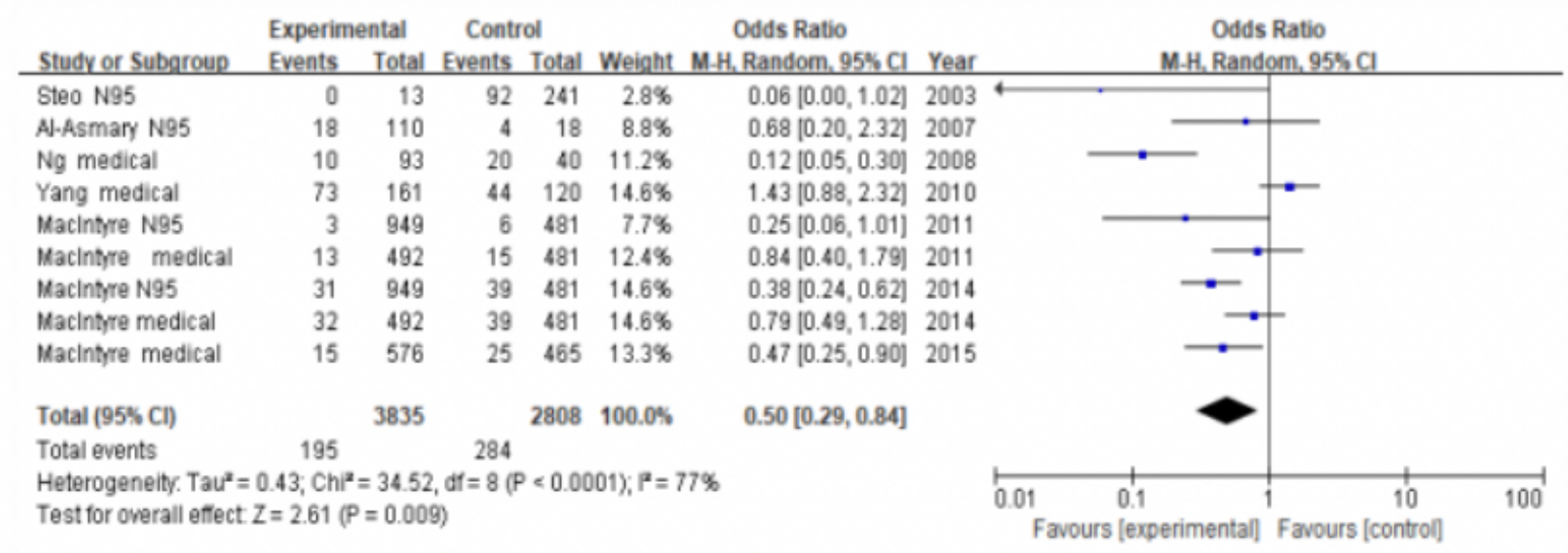

B

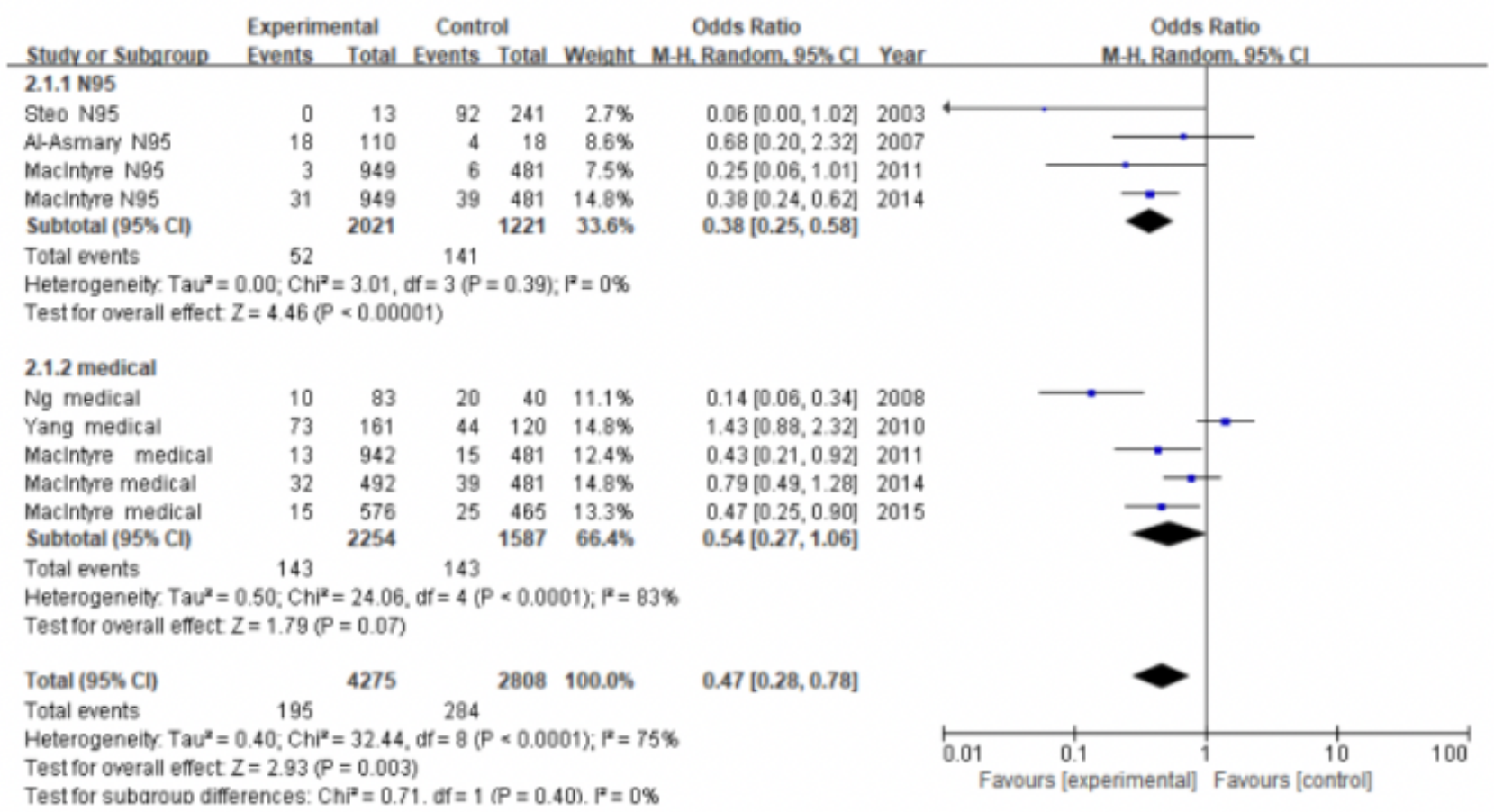

\section{Figure 4}

Meta-analysis of RCTs assessing the protective effects of N95 respirators and medical masks against respiratory infectious diseases. (A) Meta-analysis of the effect of wearing N95 respirators and medical masks for protection against respiratory infectious diseases. (B) Subgroup analysis of the effect of wearing N95 respirators and medical masks for protection against respiratory infectious diseases. 


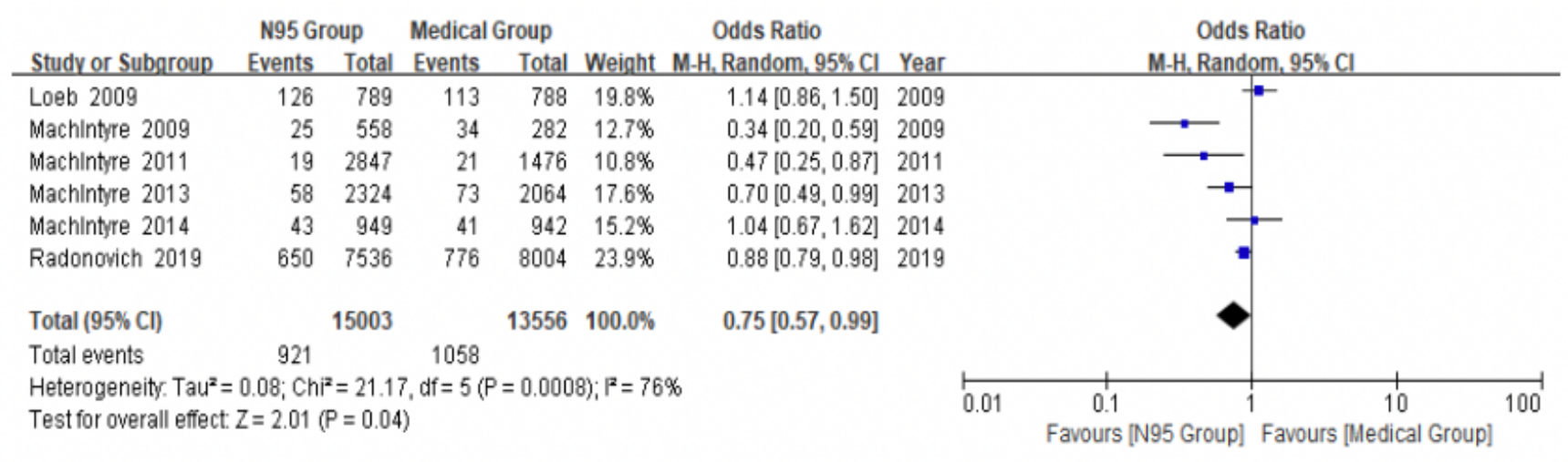

\section{Figure 5}

Meta-analysis of RCTs comparing the protective effects of medical masks and N95 respirators against respiratory infectious diseases. 
A

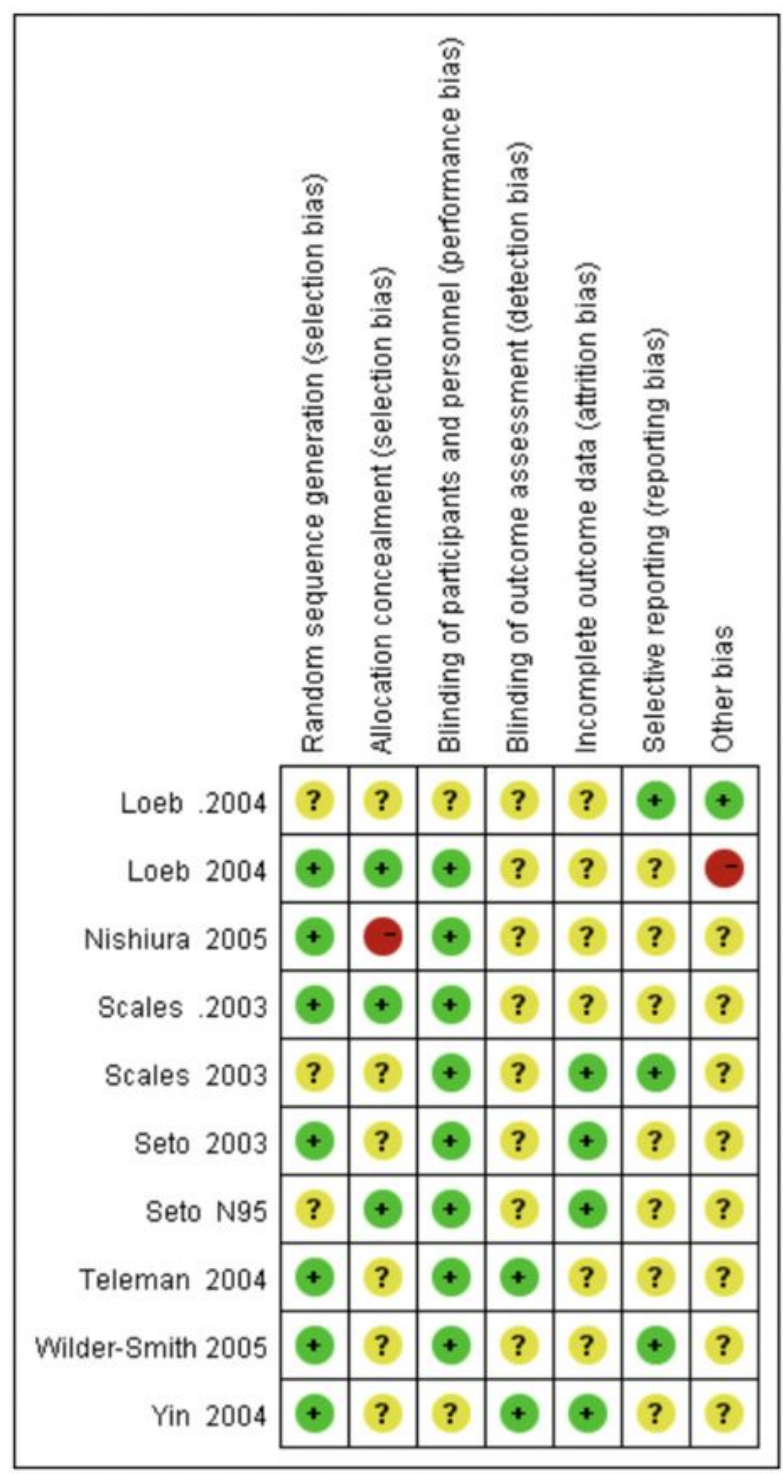

B

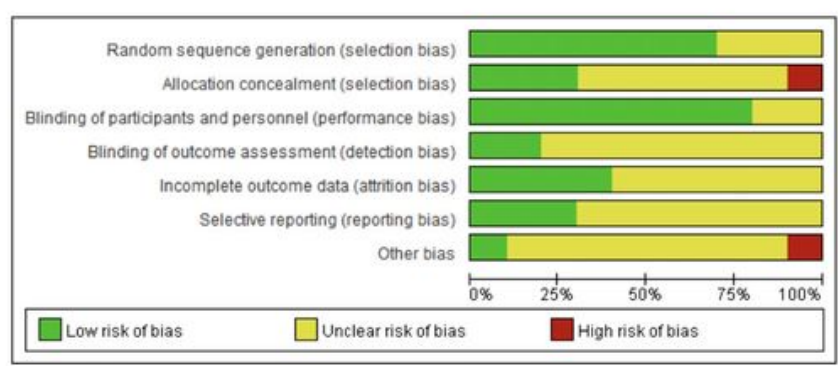

Figure 6

A. OSs received a high (red), low (green) or uncertain (yellow) risk of bias score for each of the domains.

B. Percentage of OSs with high, low or uncertain risk of bias in each domain. 


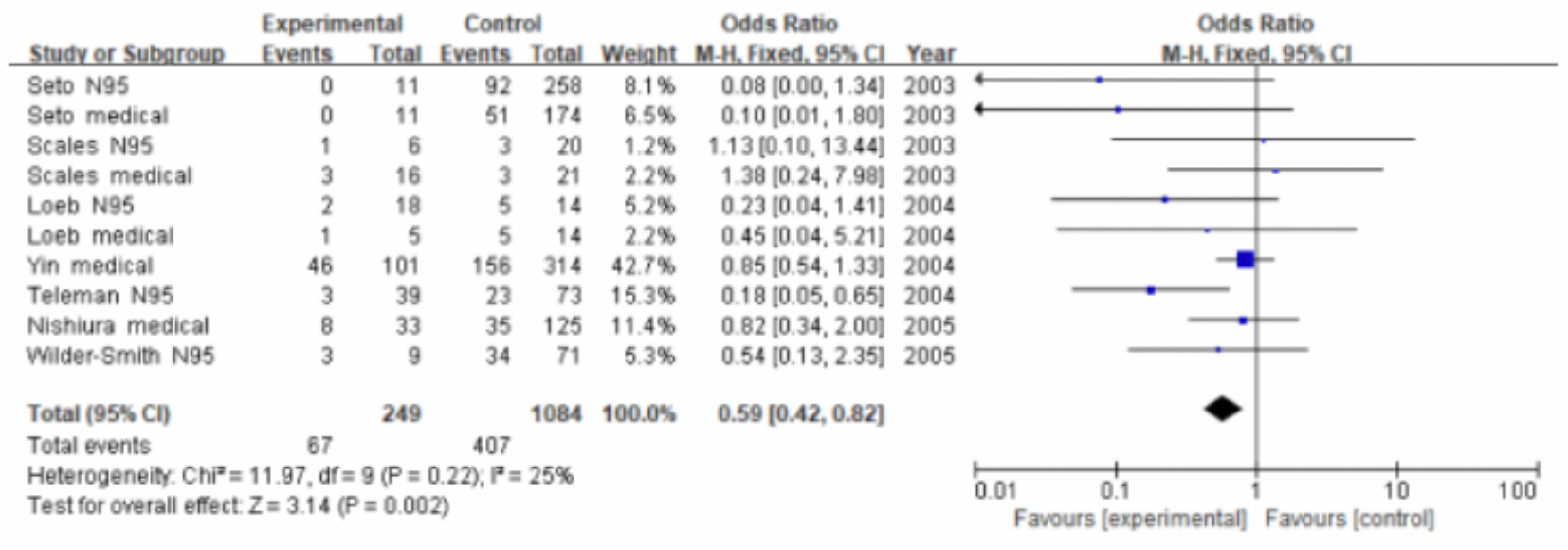

B

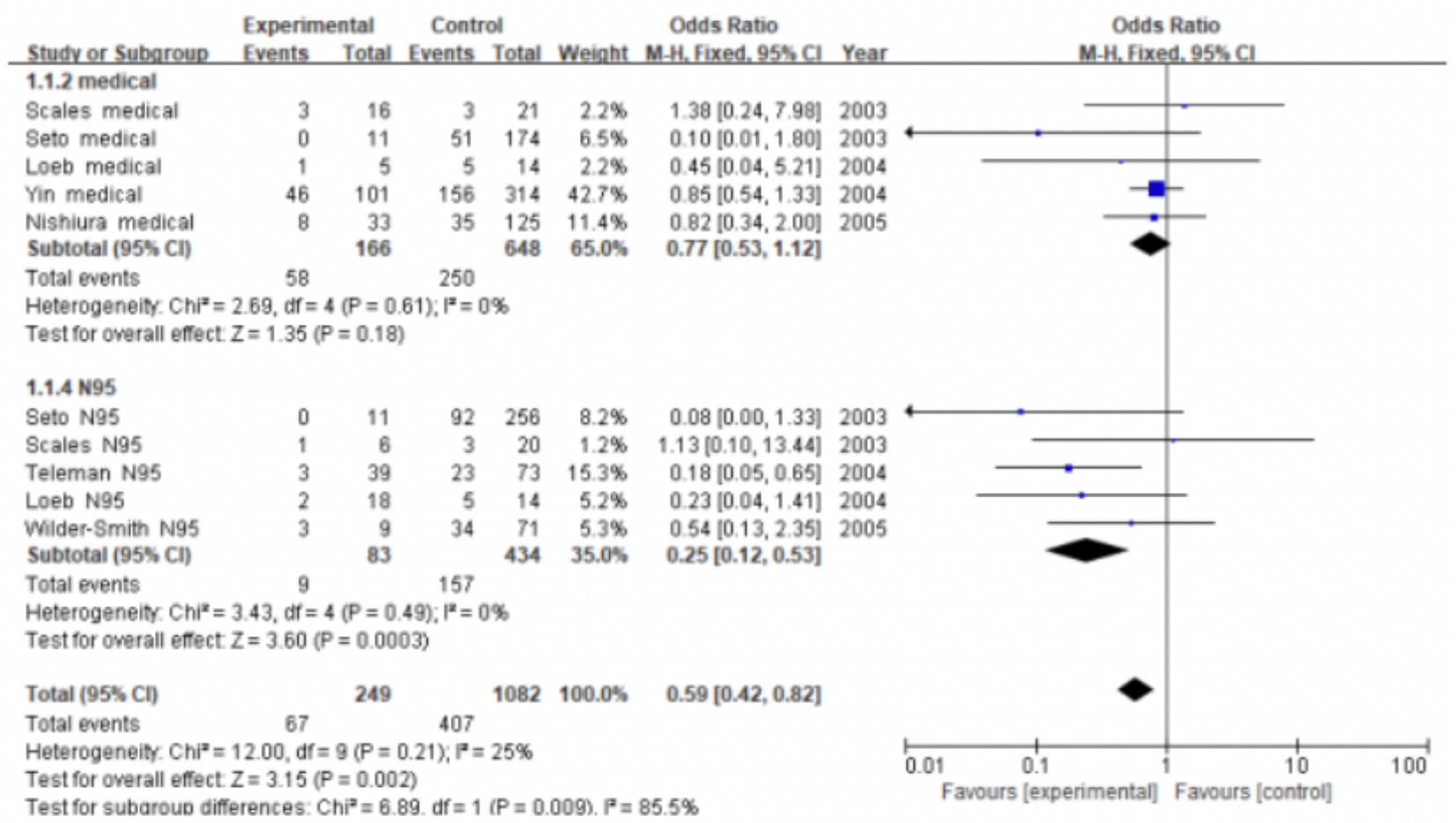

\section{Figure 7}

Meta-analysis of OSs assessing the protective effects of N95 respirators and medical masks against respiratory infectious diseases. (A) Meta-analysis of the effect of wearing N95 respirators and medical masks for protection against respiratory infectious diseases. (B) Subgroup analysis of the effect of wearing N95 respirators and medical masks for protection against respiratory infectious diseases. RCTs, randomized controlled trials; OR, odds ratio; $\mathrm{Cl}$, confidence interval; OSs, observational Studies. 